\title{
Light Hydrocarbon Geochemistry: Insight into Mississippian Crude Oil Sources from the Anadarko Basin, Oklahoma, USA
}

\author{
Ibrahim Atwah $\mathbb{D},{ }^{1,2}$ Stephen Sweet, ${ }^{2}$ John Pantano, ${ }^{3}$ and Anthony Knap ${ }^{2}$ \\ ${ }^{1}$ Department of Geology and Geophysics, Texas A\&M University, College Station, TX 77845, USA \\ ${ }^{2}$ Geochemical and Environmental Research Group, Texas A\&M University, College Station, TX 77845, USA \\ ${ }^{3}$ Pantano Keeler LLC, Butte, Montana 59701, USA \\ Correspondence should be addressed to Ibrahim Atwah; atwahiz@tamu.edu
}

Received 16 January 2019; Revised 14 February 2019; Accepted 5 March 2019; Published 14 May 2019

Academic Editor: Paolo Fulignati

Copyright $\odot 2019$ Ibrahim Atwah et al. This is an open access article distributed under the Creative Commons Attribution License, which permits unrestricted use, distribution, and reproduction in any medium, provided the original work is properly cited.

The Mississippian limestone is a prolific hydrocarbon play in the northern region of Oklahoma and the southern part of Kansas. The Mississippian reservoirs feature variations in produced fluid chemistry usually explained by different possible source rocks. Such chemical variations are regularly obtained from bulk, molecular, and isotopic characteristics. In this study, we present a new geochemical investigation of gasoline range hydrocarbons, biomarkers, phenols, and diamondoids in crude oils produced from Mississippian carbonate and Woodford Shale formations. A set of oil samples was examined for composition using highperformance gas-chromatography and mass-spectrometry techniques. The result shows a distinct geochemical fingerprint reflected in biomarkers such as the abundance of extended tricyclic terpanes, together with heptane star diagrams, and diamantane isomeric distributions. Such compounds are indicative of the organic matter sources and stages of thermal maturity. Phenolic compounds varied dramatically based on geographic location, with some oil samples being depleted of phenols, while others are intact. Based on crude oil compositions, two possible source rocks were identified including the Woodford Shale and Mississippian mudrocks, with a variable degree of mixing reported. Variations in phenol concentrations reflect reservoir fluid dynamic and water interactions, in which oils with intact phenols are least affected by water-washing conversely and crude oils depleted in phenols attributed to reservoir water-washing. These geochemical parameters shed light into petroleum migration within Devonian-Mississippian petroleum systems and mitigate geological risk in exploring and developing petroleum reservoirs.

\section{Introduction}

Petroleum production in Oklahoma from Mississippian aged reservoirs was first discovered in 1897 near oil seeps at Bartlesville, Oklahoma [1]. Since then, Mississippian carbonate reservoirs are one of the most prolific hydrocarbon resources in the Southern-Midcontinent region [2]. In recent years, new discoveries of liquid-rich hydrocarbons within unconventional tight shales have gained significant interest. Particularly, the unconventional STACK Play is one of the most active regions in Oklahoma for hydrocarbon production [3]. The acronym "STACK" stands for Sooner Trend Anadarko Canadian and Kingfisher counties. Despite the contribution of horizontal drilling and hydraulic stimulation, major geological factors control the variability in both produced hydrocarbon volume and quality.
An important factor affecting hydrocarbon richness in Mississippian reservoir is due to source rock heterogeneity. The Woodford Shale is an organic-rich source of hydrocarbon that charged Mississippian reservoirs, together with Mississippian mudrocks such as Caney Shale $[4,5]$. Typically, identifying petroleum sourcing is achieved using a collection of geochemical tools such as molecular and isotopic characteristics. Those include biomarkers together with stable carbon isotopes of saturate and aromatic hydrocarbons $[5,6]$. Currently, light hydrocarbon markers remain underutilized in crude oil recovered from Mississippian reservoirs. Oil/oil correlations, together with hydrocarbon migration and maturity assessment, can be further refined by utilizing the light hydrocarbon markers.

Light hydrocarbon geochemistry is an effective tool for refining petroleum systems especially with processes related 
to petroleum migration and accumulation. Here, we present new geochemical data of light hydrocarbons produced from Mississippian reservoirs across the Anadarko Basin in Oklahoma. Data suggest different sources of hydrocarbons, with various thermal maturity stages. Moreover, these data shed light into factors affecting petroleum accumulation in Mississippian reservoirs such as water-washing and petroleum mixing.

\section{Geological Settings}

The Anadarko Basin is classified as a foreland basin extending to the north forming the Anadarko Shelf (Figure 1). The basin is bordered to the east by the Nemaha Uplift and to the south by the Wichita-Amarillo Uplift (Figure 1(a)). The Anadarko depocenter is situated to the southwestern area of Oklahoma, with a general trend of deepening formations to the south (Figure 1(b)). According to Johnson [7], the geological evolution of the Anadarko Basin can be divided into four phases. The first phase during Early Cambrian marks the creation of the basin as failed arm-rifting known Southern Oklahoma Aulacogen during the Early Cambrian [8]. The major igneous activity resulted in the emplacement of basement rock forming the Anadarko depocenter and Wichita Uplift [9]. The second phase marked geologically stable passive margin settings during the Late Cambrian through Mississippian times, known as the epeirogenic episode [7]. This phase deposited a thick session of carbonate interbedded with shales and clastic sediments (Figure 1) [10-12]. The third phase of the Anadarko Basin is an orogenic episode during Late Mississippian to Pennsylvanian times, with a major tectonic shift from a passive to a foreland basin setting $[7,13,14]$. Such a tectonic shift is attributed to the collision of the North American plate with supercontinent of Gondwana, accompanied by faulting, folding, uplift, and erosion marking the regional pre-Pennsylvanian unconformity [7, $15,16]$. During the Pennsylvanian, thick sediments of dominantly clastic rocks and shales were deposited across the Anadarko Basin reaching a thickness up to $18,000 \mathrm{ft}$ of marine sediments (Figure 1) [7]. Lastly, the fourth phase reflects an epeirogenic episode of the Anadarko Basin spanning from Permian through the present day, during which dramatic tectonic activities have ended, and slow subsidence took place due to lithosphere cooling [7, 17]. Consequently, Permian sediments are predominantly erosional sediments consisting of red beds and evaporites with a total thickness of approximately $7,000 \mathrm{ft}[7,17]$.

\section{Materials and Methods}

3.1. Study Area and Sampling. The study area extends across two major Mississippian oil plays, the Mississippi Lime and STACK Plays (Figure 1(b)). Areal coverage includes Alfalfa, Woods, Canadian, Kingfisher, Blaine, Payne, and Logan counties. From a geological perspective, all counties are located within the Anadarko Basin province except for Logan and Payne counties which are part of the shallow Cherokee Platform. The Nemaha Uplift is a major structural feature dividing the Cherokee Platform from the Anadarko Basin province.

Crude oil samples were collected from Mississippian reservoirs, as well as the Woodford Shale zone. Figure 2 shows a generalized stratigraphic column of the Anadarko Basin, and major source rocks and all examined crude oils are produced from Devonian-Mississippian petroleum systems. Well-head fluid samples were collected at the separator in $240 \mathrm{ml}$ borosilicate glass bottles and tightly sealed with a PTFE-lined cap. Table 1 lists the 16 crude oil samples with key bulk characteristics in this study. An aliquot of the crude oil sample was dissolved in hexane to precipitate asphaltenes; dissolved hydrocarbons in hexane were further fractionated using silica gel column chromatography into saturate, aromatic, and resin fractions. All samples are produced from horizontal wells that have been stimulated with hydraulic fracturing; therefore, the reservoir listed in Table 1 represents the landing zone of the well and not necessarily the source of the produced oils.

3.2. High-Resolution Gas Chromatography. Whole-oil aliquots were analyzed on an Agilent 7890 gas chromatograph (GC) equipped with a flame ionization detector (FID). The GC features a Petrocol DH $50 \mathrm{~m} \times 0.20 \mathrm{~mm}$ ID fused silica capillary column coated with $0.50 \mu \mathrm{m}$ of nonpolar methyl silicone. Helium was used as a carrier gas with the column flow set at $1.3 \mathrm{ml} / \mathrm{min}$, whereas the GC oven temperature is programmed from $35^{\circ} \mathrm{C}$ to $375^{\circ} \mathrm{C}$ at a temperature ramp of $2^{\circ} \mathrm{C} / \mathrm{min}$. The analysis was performed under a split injection mode with a split ratio of 50:1 carrier gas to a sample mixture for crude oil. A Supelco quantitative reference standard mix of gasoline range hydrocarbons was used to identify 32 compounds ranging from normal butane to normal nonane.

3.3. Gas Chromatography Mass Spectrometry. Saturate fractions of crude oil samples were analyzed on an Agilent 7890 gas chromatograph interfaced to an Agilent 5977 mass selective detector (GC-MS). The GC-MS is equipped with a DB-1 fused silica $60 \mathrm{~m} \times 0.25 \mathrm{~mm} \times 0.25 \mu \mathrm{m}$ column with helium carrier gas at a flow rate of $1.2 \mathrm{ml} / \mathrm{min}$, pressure of $19.93 \mathrm{psi}$, and an average velocity of $20.538 \mathrm{~cm} / \mathrm{sec}$. The GC-MS is operated on splitless injection, with the oven programmed at an initial temperature of $35^{\circ} \mathrm{C}$ for 2 minutes and increased at a rate of $2^{\circ} \mathrm{C} /$ minute to $80^{\circ} \mathrm{C}$, then $3^{\circ} \mathrm{C} /$ minute from $80^{\circ} \mathrm{C}$ to $320^{\circ} \mathrm{C}$, followed by 15 minutes at $320^{\circ} \mathrm{C}$. The analysis was carried out using $70 \mathrm{eV}$ ionization potential. GC/MS data were acquired in single ion monitoring (SIM) mode with 50-100 msec dwell times for ions of interest. Compound ratios were calculated directly from peak areas or peak heights of targeted markers and compared with internal standards.

\section{Results and Discussion}

4.1. Bulk Parameters. Crude oils exhibit slight differences in bulk parameters that are consistent with the type of fluid, in which the majority of the samples are classified as medium oil. Table 1 lists key bulk parameters of the crude oils, including fluid type, API gravity, and SARA component classes. 


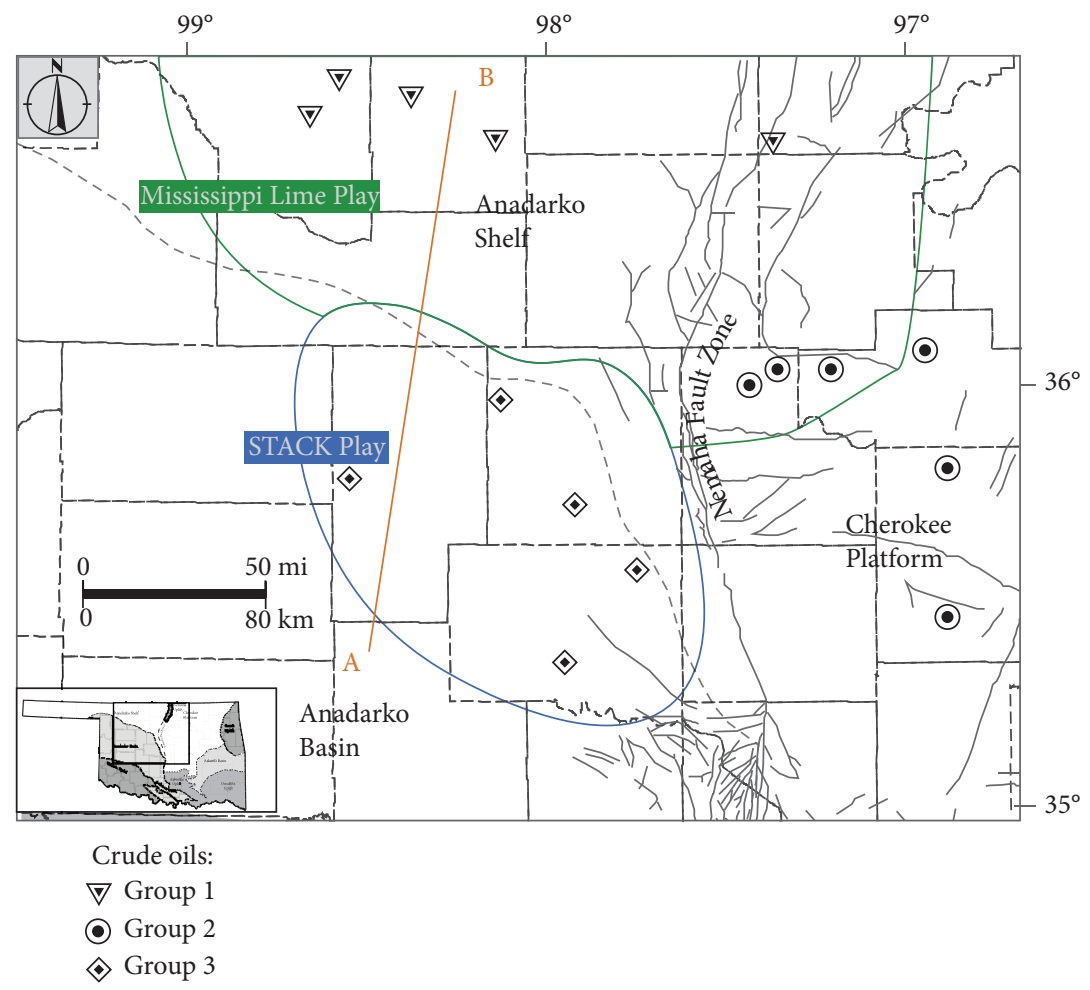

(a)

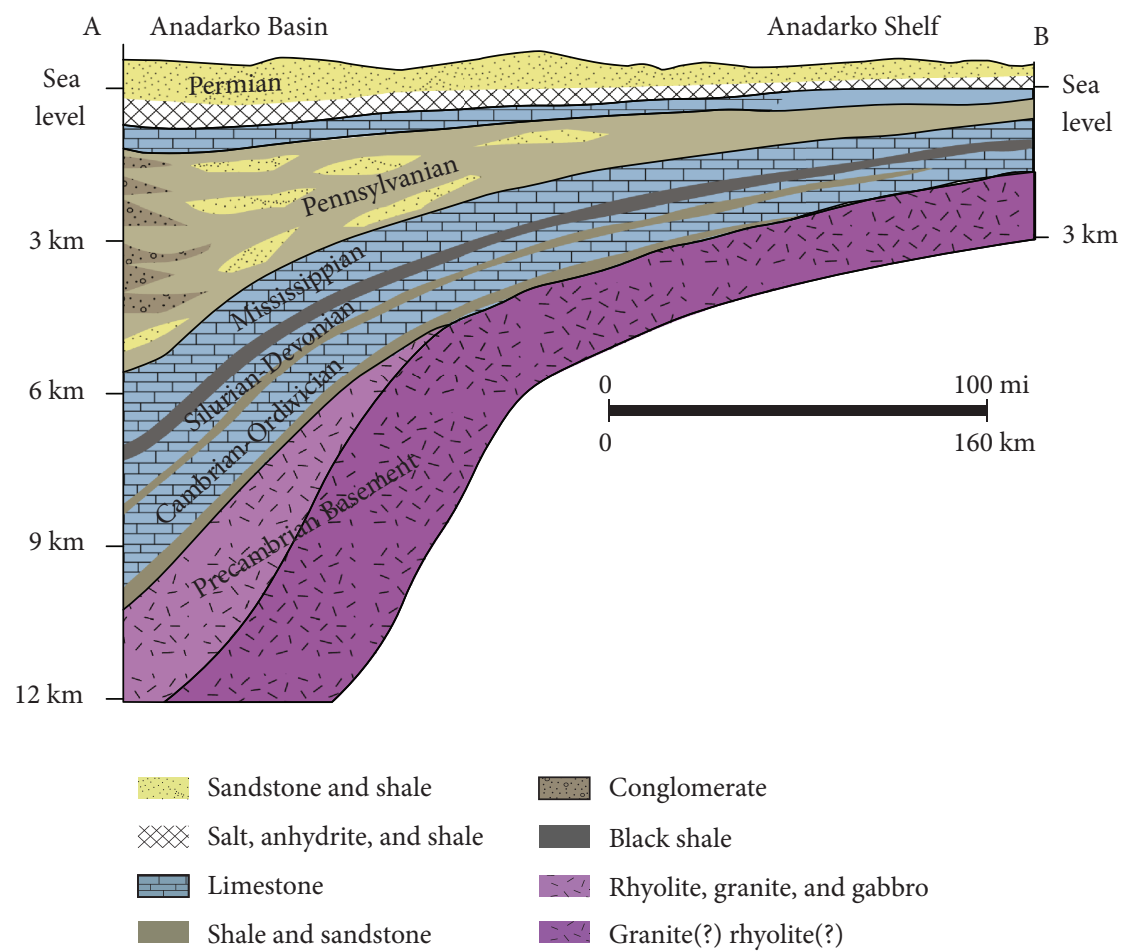

(b)

FIgURE 1: (a) Map showing the location of examined crude oil samples relative to major geological features and hydrocarbon plays in Oklahoma; the dotted line marks the borders of the Anadarko Basin. (b) A generalized cross-section of the Anadarko Basin shown south to north trend of the basin layers. 


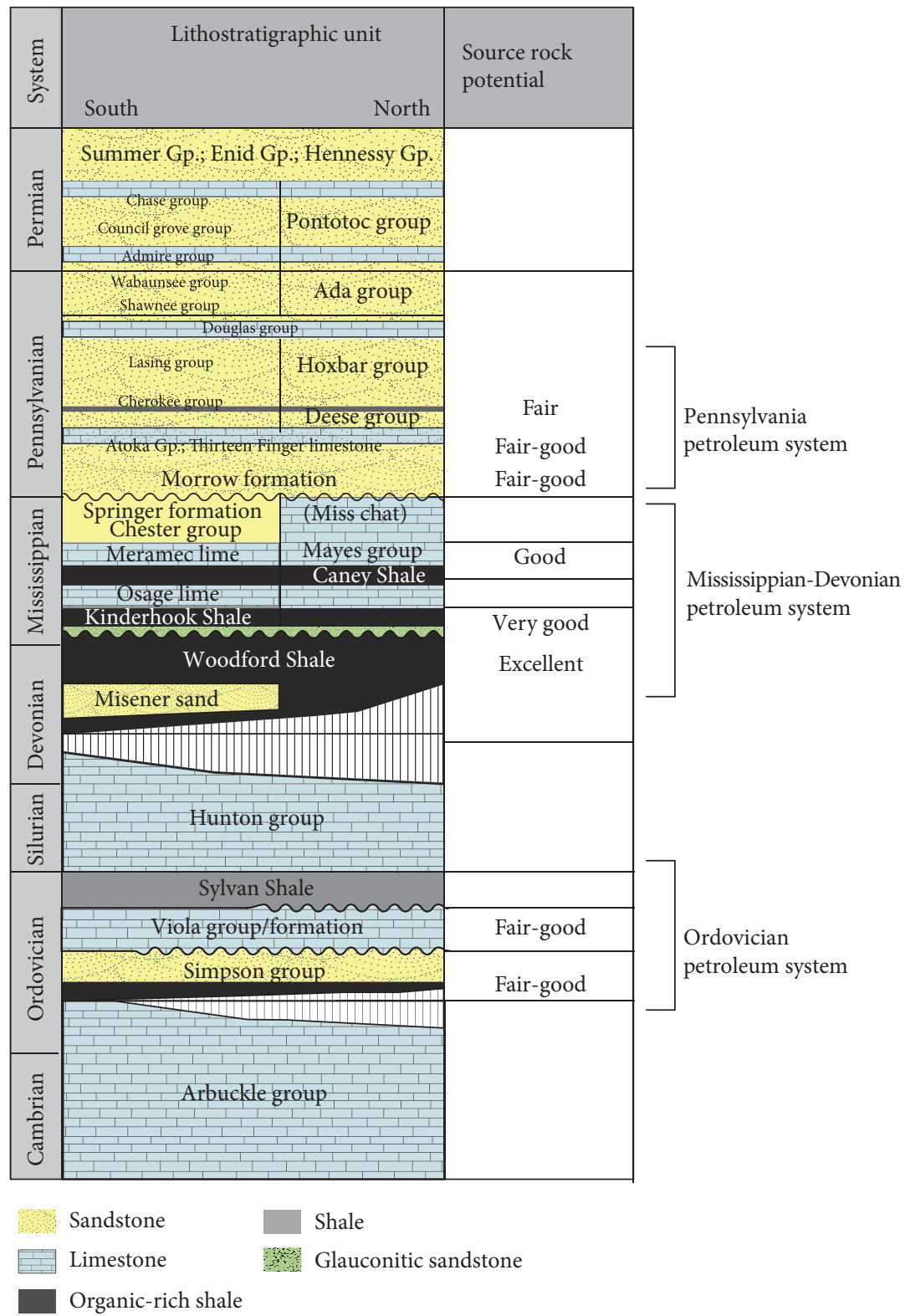

FIGURE 2: Generalized stratigraphic column of the Anadarko Basin formations with major source rocks and petroleum systems; samples in this study are from the Mississippian-Devonian petroleum systems.

API gravity values ranged from 21.73 to 49.39 , as reflected in the fluid type, in which lower API values are associated with heavier black oils and higher API values from light oils. All of the oil samples are dominated by saturate hydrocarbons relative to aromatic, resin, and asphaltenes. Heavier crude oils such as Woo-1 were higher in asphaltene content relative to the rest of the oil samples.

The crude oil bulk characteristic is a useful descriptive source of data with some inherent limitations. The abundance of the saturated hydrocarbon type class is expected in thermogenic hydrocarbon expelled from petroleum source rocks. Such enrichment in saturated hydrocarbons is usually observed in naturally produced crude oil, as well as in immiscible oil generated under hydrous pyrolysis experimental conditions [18]. However, the source of hydrocarbons cannot be determined solely from bulk parameters; therefore, examination of molecular data discussed below can identify hydrocarbon sources.

\subsection{Light Hydrocarbons}

4.2.1. Source Parameters. Heptane $\left(\mathrm{C}_{7}\right)$ variability reflected the geographic location among the three distinct oil groups. Table 2 lists the ratios used for constructing the oil correlation star diagram (OCSD) and oil transformation star diagram (OTSD) [19]. Group 1 samples located within the Anadarko Shelf exhibited a unique fingerprint of the $\mathrm{C}_{7}$ OCSD (Figure 3), specifically, these oils are enriched in the 3,3-dimethylpentane isomer relative to the rest of heptane isomers. Similarly, enrichment in 2,2-dimethylpentane and 
TABLE 1: Bulk compositional and physical characteristics of examined crude oil samples.

\begin{tabular}{|c|c|c|c|c|c|c|c|}
\hline Sample ID & Reservoir* & API & $\% \mathrm{SAT}^{+}$ & $\% \mathrm{ARO}^{+}$ & $\% \mathrm{POL}^{+}$ & $\% \mathrm{ASP}^{+}$ & Type \\
\hline \multicolumn{8}{|l|}{ Group 1} \\
\hline Alf-1 & Mississippian & 36.12 & 78.2 & 14.3 & 5.4 & 2.1 & Medium oil \\
\hline Alf-2 & Mississippian & 37.39 & 63.4 & 28.7 & 3.4 & 4.5 & Medium oil \\
\hline Woo-1 & Mississippian & 28.1 & 58.1 & 21.7 & 11.1 & 9.1 & Black oil \\
\hline Woo-2- & Mississippian & 21.73 & 50.5 & 24.2 & 14.8 & 10.5 & Black oil \\
\hline Kay-1 & Mississippian & 48.91 & 69.1 & 29.2 & 0.9 & 0.8 & Condensate \\
\hline \multicolumn{8}{|l|}{ Group 2} \\
\hline Lin-1 & Woodford & 38.45 & 77 & 14.2 & 4.5 & 4.3 & Medium oil \\
\hline Lin-2 & Mississippian & 33.24 & 78.3 & 11.2 & 7.7 & 2.8 & Medium oil \\
\hline Log-1 & Mississippian & 38.12 & 75.5 & 18.9 & 3.5 & 2.1 & Medium oil \\
\hline $\log -2$ & Mississippian & 38.14 & 81.2 & 13.5 & 4.2 & 1.1 & Medium oil \\
\hline Pay-1 & Mississippian & 38.27 & 66.6 & 17.8 & 8.4 & 7.2 & Medium oil \\
\hline Pay-2 & Woodford & 34.21 & 75.7 & 18.7 & 3.8 & 1.8 & Medium oil \\
\hline \multicolumn{8}{|l|}{ Group 3} \\
\hline Can-1 & Mississippian & 32.54 & 70.8 & 21.4 & 5.2 & 2.6 & Medium oil \\
\hline Can-2 & Mississippian & 33.38 & 61.8 & 30.1 & 3.3 & 4.8 & Medium oil \\
\hline Kin-1 & Mississippian & 35.6 & 64.5 & 28.7 & 5 & 1.8 & Medium oil \\
\hline Kin-2 & Mississippian & 33.71 & 68.8 & 22.1 & 4.7 & 4.4 & Medium oil \\
\hline Bla-1 & Mississippian & 49.39 & 87.5 & 10.9 & 1.1 & 0.5 & Condensate \\
\hline
\end{tabular}

${ }^{*}$ Reservoir indicates the landing zone of the horizontal well, and not necessarily the actual source of the oil. ${ }^{+}$SAT: weight percentage of saturate hydrocarbons; ARO: weight percentage of aromatic hydrocarbons; POL: weight percentage of polar resin compounds (NSO); ASP: weight percentage of asphaltenes.

TABLE 2: Key light hydrocarbon ratios of crude oil samples sensitive to source, transformation, and maturity.

\begin{tabular}{|c|c|c|c|c|c|c|c|c|c|c|c|c|c|c|c|}
\hline \multirow{2}{*}{ Sample ID } & \multicolumn{5}{|c|}{ Oil-correlation parameters } & \multicolumn{8}{|c|}{ Oil-transformation ratio } & \multicolumn{2}{|c|}{ Maturity } \\
\hline & 2,3-DMP & 2,2-DMP & EtP & 3,3-DMP & 2,4-DMP & TR-1 & TR-2 & TR-3 & TR-4 & TR-5 & TR-6 & TR-7 & TR-8 & $\mathrm{C}_{7}$ ratio & iso $_{7}$ ratio \\
\hline \multicolumn{16}{|l|}{ Group 1} \\
\hline Alf- 1 & 1.12 & 0.33 & 1.13 & 0.31 & 0.44 & 0.01 & 0.89 & 0.79 & 0.61 & 0.71 & 1.64 & 1.20 & 0.96 & 34.0 & 0.9 \\
\hline Alf-2 & 1.06 & 0.47 & 1.10 & 0.49 & 0.56 & 0.15 & 0.98 & 0.88 & 0.76 & 0.83 & 1.42 & 1.15 & 0.87 & 50.3 & 1.5 \\
\hline Woo-1 & 1.12 & 0.32 & 1.00 & 0.36 & 0.42 & 0.01 & 0.69 & 0.66 & 0.57 & 0.62 & 1.60 & 1.03 & 0.58 & 57.2 & 1.7 \\
\hline Woo-2- & 1.06 & 0.36 & 1.10 & 0.52 & 0.61 & 0.08 & 0.84 & 0.79 & 0.63 & 0.61 & 1.36 & 1.02 & 0.63 & 45.3 & 1.3 \\
\hline Kay-1 & 1.09 & 0.31 & 1.31 & 0.40 & 0.52 & 0.15 & 0.60 & 0.71 & 0.68 & 0.66 & 1.21 & 0.92 & 0.65 & 22.7 & 0.9 \\
\hline \multicolumn{16}{|l|}{ Group 2} \\
\hline Lin-1 & 1.03 & 0.23 & 1.57 & 0.30 & 0.57 & 0.01 & 0.64 & 0.78 & 0.51 & 0.55 & 1.47 & 1.42 & 1.06 & 16.9 & 0.8 \\
\hline Lin-2 & 1.12 & 0.37 & 1.20 & 0.51 & 0.44 & 0.16 & 0.96 & 0.75 & 0.53 & 0.65 & 1.67 & 1.23 & 0.90 & 15.1 & 0.5 \\
\hline $\log -1$ & 1.19 & 0.27 & 1.80 & 0.31 & 0.48 & 0.15 & 0.72 & 0.61 & 0.43 & 0.53 & 1.37 & 1.09 & 0.87 & 23.9 & 0.7 \\
\hline $\log -2$ & 1.13 & 0.30 & 1.26 & 0.48 & 0.44 & 0.09 & 0.78 & 0.68 & 0.46 & 0.58 & 1.20 & 1.02 & 0.86 & 18.5 & 0.5 \\
\hline Pay-1 & 1.08 & 0.24 & 1.43 & 0.55 & 0.46 & 0.05 & 0.86 & 0.77 & 0.52 & 0.66 & 1.50 & 1.25 & 0.83 & 27.1 & 0.8 \\
\hline Pay-2 & 1.21 & 0.26 & 1.13 & 0.35 & 0.41 & 0.02 & 0.84 & 0.70 & 0.50 & 0.61 & 1.55 & 1.21 & 0.95 & 25.6 & 0.8 \\
\hline \multicolumn{16}{|l|}{ Group 3} \\
\hline Can-1 & 0.85 & 0.87 & 0.79 & 1.03 & 0.85 & 0.21 & 0.86 & 0.75 & 0.55 & 0.66 & 1.22 & 1.49 & 0.67 & 28.9 & 0.4 \\
\hline Can-2 & 0.83 & 0.65 & 0.79 & 1.06 & 0.83 & 0.18 & 0.75 & 0.76 & 0.77 & 0.75 & 1.23 & 1.30 & 0.59 & 31.0 & 0.7 \\
\hline Kin-1 & 0.94 & 0.70 & 0.78 & 1.08 & 0.94 & 0.25 & 0.81 & 0.68 & 0.76 & 0.86 & 1.24 & 1.22 & 0.70 & 52.0 & 1.8 \\
\hline Kin-2 & 0.91 & 0.73 & 0.79 & 1.06 & 0.91 & 0.27 & 0.71 & 0.66 & 0.62 & 0.68 & 1.33 & 1.44 & 0.76 & 29.6 & 1.2 \\
\hline Bla-1 & 0.85 & 0.87 & 0.79 & 1.03 & 0.85 & 0.21 & 0.86 & 0.75 & 0.55 & 0.66 & 1.22 & 1.49 & 0.67 & 28.9 & 0.4 \\
\hline
\end{tabular}

P1:2,2-dimethylpentane + 2,3-dimethylpentane + 2,4-dimethylpentane + 3,3-dimethylpentane + 3-ethylpentane; 2,2-DMP: 2,2-dimethylpentane/P1; 2,3-DMP: 2,3-dimethylpentane/P1; 2,4-DMP: 2,4-dimethylpentane/P1; 3,3-DMP: 3,3-dimethylpentane/P1; EtP: 3-ethylpentane/P1; X: 1,1-dimethylcyclopentane; P2: 2-methylhexane + 3-methylhexane; TR1: toluene/X; TR2: nC7/X; TR3: 3-methylhexane/X; TR4: 2-methylhexane/X; TR5: P2/X; TR6: 1-cis-2dimethylcyclopentane/X; TR7: 1-trans-3-dimethylcyclopentane/X; TR8: P1/P2; $\mathrm{C}_{7}$ ratio: 100*n-heptane/cyclohexane + 2-methylhexane + 1,1dimethylcyclopentane (DMCP) + 3-methylhexane + 1-cis-3-DMCP + 1-trans-3DMCP + 1-trans-2-DMCP + n-heptane + methylcyclohexane; iso C $_{7}$ ratio: 2-methylhexane + 3-methylhexane/1-cis-3-DMCP + 1-trans-3DMCP + 1-trans-2-DMCP. 

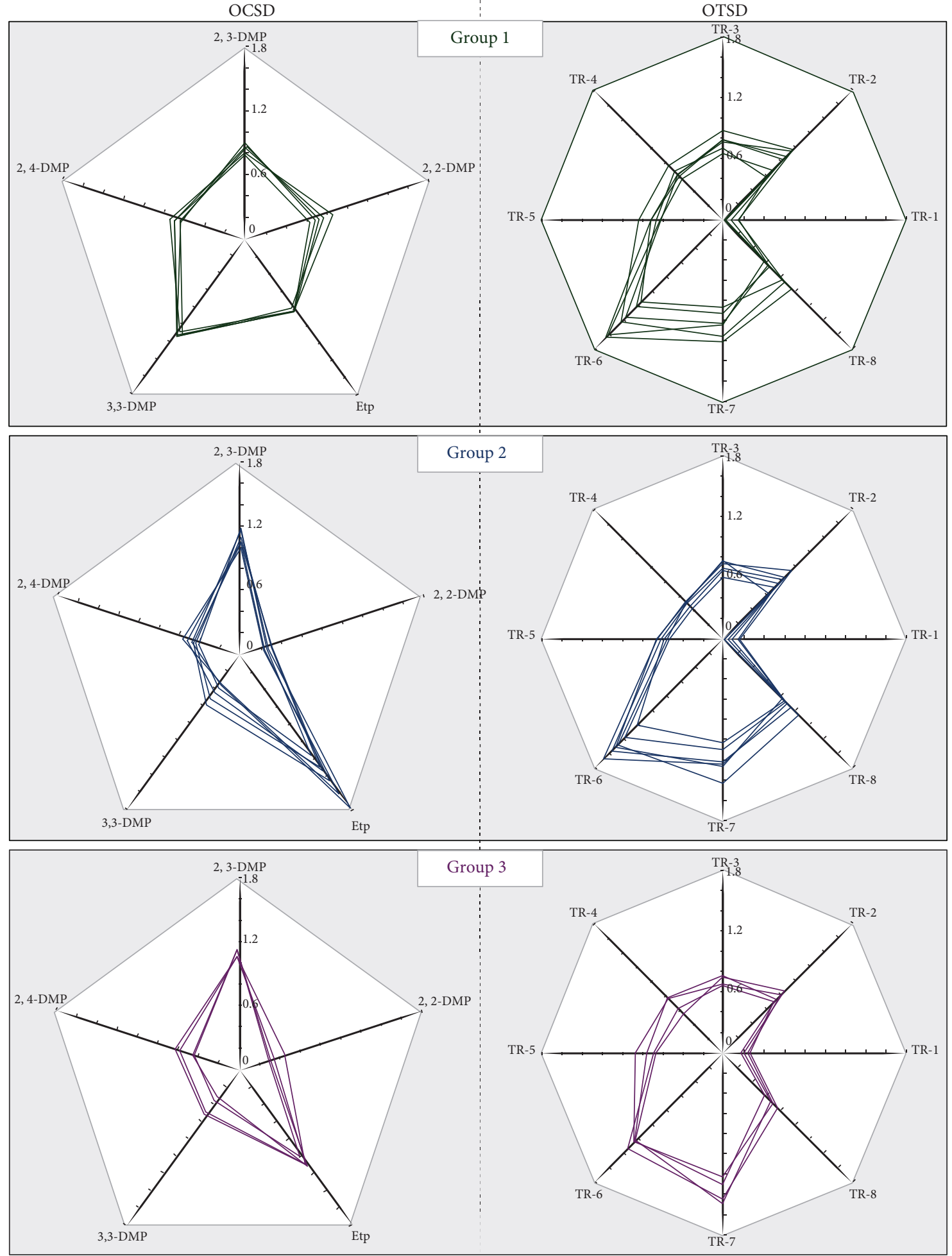

FIgURE 3: Oil correlation star diagrams (OCSD) (left) and oil transformation star diagrams (OTSD) (right). P1: 2,2-dimethylpentane $+2,3$ dimethylpentane + 2,4-dimethylpentane + 3,3-dimethylpentane + 3-ethylpentane. 2,2-DMP: 2,2-dimethylpentane/P1; 2,3-DMP: 2,3-dimethylpentane/P1; 2,4-DMP: 2,4-dimethylpentane/P1; 3,3-DMP: 3,3-dimethylpentane/P1; EtP: 3-ethylpentane/P1; X: 1,1-dimethylcyclopentane; P2: 2-methylhexane + 3-methylhexane; TR1: toluene/X; TR2: $n \mathrm{C}_{7} / \mathrm{X}$; TR3: 3-methylhexane/X; TR4: 2methylhexane/X; TR5: P2/X; TR6: 1-cis-2-dimethylcyclopentane/X; TR7: 1-trans-3-dimethylcyclopentane/X; TR8: P1/P2; C 7 ratio: $100 * \mathrm{n}$-heptane/cyclohexane + 2-methylhexane + 1,1-dimethylcyclopentane (DMCP) + 3-methylhexane + 1-cis-3-DMCP + 1-trans$3 \mathrm{DMCP}+1$-trans-2-DMCP $+n$-heptane + methylcyclohexane; isoC ${ }_{7}$ ratio: 2-methylhexane + 3-methylhexane/1-cis-3-DMCP + 1-trans-3DMCP + 1-trans-2-DMCP [19]. 
2,4-dimethylpentane is observed within Mississippian oils located on the Anadarko Shelf. Additionally, group 1 oils varied the most for 2,2-dimethylpentane, followed by 3,3-dimethylpentane isomers (Figure 3). However, even with those variations, the overall star diagram fingerprint is unique to Mississippian produced oils from the Anadarko Shelf compared to other oil groups (Figure 3). Group 2 oils located in Central Oklahoma showed a narrow OCSD pattern, with significant enrichment in 3-ethylpentane and relatively moderate variance of 3,3-dimethylpentane (Table 2). Group 3 oils displayed more subtle variability where some oils are enriched in 3,3-dimethylpentane and relatively lower in 2,4-dimethylpentane isomer, while other oils are enriched in 2,4-dimethylpentane isomers and depleted in 3,3-dimethylpentane isomers. The OCSD fingerprint of group 3 crude oils is slightly wider compared to group 2 oils, with higher values at 2,4-dimethylpentane and 2,2-dimethylpentane isomers (Table 2). In contrast, group 3 oils have an intermediate 3-ethylpentane abundance compared to group 3 and group 1 crude oils (Figure 3). Among group 3 oils, the highest variance is observed at the 3,3-dimethylpentane ratio.

The observed variation of star diagram fingerprints across crude oil groups is a function of source rock and evaporative fractionation. Mango [20] reported that the formation of light hydrocarbons in crude oil is via metalcatalyzed steady-state kinetic reaction from the parent kerogen. Further, Mango [20] observed that while the absolute concentration of light hydrocarbons from the same source varied by orders of magnitude, certain ratios of light hydrocarbons remained invariable, such as the sum of 2-methylhexane and 2,3-dimethylpentane relative to the sum of 3-methylhexane and 2,4-dimethylpentane (K1). To explain the invariance of the $\mathrm{C}_{6}-\mathrm{C}_{7}$ hydrocarbons, Mango [20] postulated that light hydrocarbons originate from a higher saturated hydrocarbon and the presence of metal catalysts will result in a similar rate of reaction for homologous series. Since OCSD parameters are based on polybranched $\mathrm{C}_{7}$ alkanes, those ratios in theory would follow the invariance observed by Mango [20]. In examined crude oils, the variations in OCSD fingerprints between group 1 and group 2 are clearly indicating two different sources of hydrocarbons (Figure 3), whereas group 3 presumably is a mix of the two end-members or from a third source. Within the Anadarko Basin, a number of source rocks have been studied ranging in age from Cambrian to Pennsylvanian $[5,6]$. Observations from light hydrocarbon source parameters are discussed in the biomarker section below.

4.2.2. Alteration Assessment. The oil transformation star diagrams (OTSD) are illustrated in Figure 3, with ratios used to construct the diagrams listed in Table 2. In all the oil samples, lowest ratio values are observed at TR-1 ranging from 0.01 to 0.27 (Table 2), with group 3 samples exhibiting the highest TR-1 values compared to the other two groups. The TR-1 ratio compares the abundance of toluene to 1,1-dimethylcyclopentane. Overall, group 1 and group 2 showed a relatively similar OTSD pattern maximizing at TR-7 followed by TR-6, whereas group 3 highest ratio coexists at TR-6 and TR-7 followed by TR- 5 .

Although light hydrocarbons are controlled by the organic matter source, secondary alterations can influence light hydrocarbon distribution (i.e., biodegradation, waterwashing, thermal maturity, and evaporation). The oil transformation star diagram is a multivariate plot in polar coordinates developed by Halpern to combine different ratios based on $\mathrm{C}_{4}-\mathrm{C}_{7}$ hydrocarbons [19]. The apparent depletion in TR-1 in the oil samples is related to the effect of water-washing, which is captured by using the ratio of toluene relative to 1,1-dimethylcyclopentane (toluene is more water-soluble, so a decreasing trend in TR-1 indicated water-washing). From OTSD, it is clear that water-washing effects occurred, but at different magnitudes, group 1 and group 2 are severely water-washed while group 3 is relatively slightly washed. No crude oil exhibited any evidence of microbial biodegradation as observed from the high values of the transformation values ranging from TR-2 to TR- 8 (Table 2). Water-washing is usually associated with biodegradation; however, some oils can be water-washed without undergoing biodegradation [21]. In the Anadarko Basin, variation in toluene abundance has been observed with a uniquely decreasing trend moving away from the basin depocenter towards the shallower shelf area; such a trend indicates long-distance migration of hydrocarbons [22]. Evidence from phenol compounds further supports the different degrees of water-washing (see Phenols). The parameter TR-6 compares compounds with a largely differing boiling point to assess hydrocarbon loss due to evaporation, which can be due to poor sample handling or due to evaporative fractionation during oil migration in the subsurface $[19,23]$. Most of the oils exhibit high values of TR- 6 overall, suggesting a minimal effect of hydrocarbon loss due to evaporation.

4.2.3. Thermal Maturity. Thermal maturity is estimated using heptane and isoheptane ratios (listed in Table 2). The heptane ratio ranged from 15.1 to 57.2, and isoheptane ranged from 0.4 to 1.8 .

Figure 4(a) reflects these data in a cross-plot comparing the heptane versus isoheptane ratio with maturity levels according to Thompson [24]. Group 1 exhibited the highest thermal maturity level followed by group 3 , whereas group 2 was the least mature based on heptane and isoheptane ratios (Figure 4(a)).

Light hydrocarbons are a useful geochemical tool to evaluate thermal maturity. A number of light hydrocarbon$\left(\mathrm{C}_{6}-\mathrm{C}_{7}\right)$ based maturity parameters have been published in the literature, pioneered by Hunt et al. [25]. These authors observed that certain ratios of light hydrocarbons such as 2,2-dimethylbutane/2,3-dimethylbutane tend to increase with increasing depth. Similarly, Thompson introduced the heptane ratio as a maturity parameter, which is calculated by the ratio of $n$-heptane to the sum of different heptane isomers [24]. Thomson defined stages for maturity assessment of oils based on heptane ratio as follows: the isoheptane ratio from 18 to 22 is normal uncracked oil, 22 to 30 is classified as mature oil, and heptane ratio $>30$ is classified as supermature [24]. The variability of heptane ratios in the different oils 


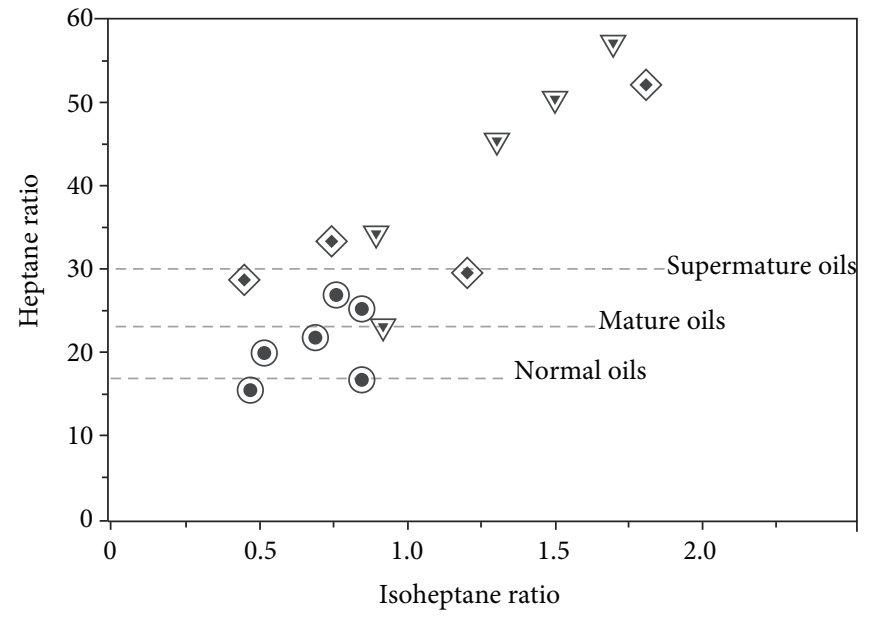

Crude oils:

$\nabla$ Group 1

- Group 2

$\diamond$ Group 3

(a)

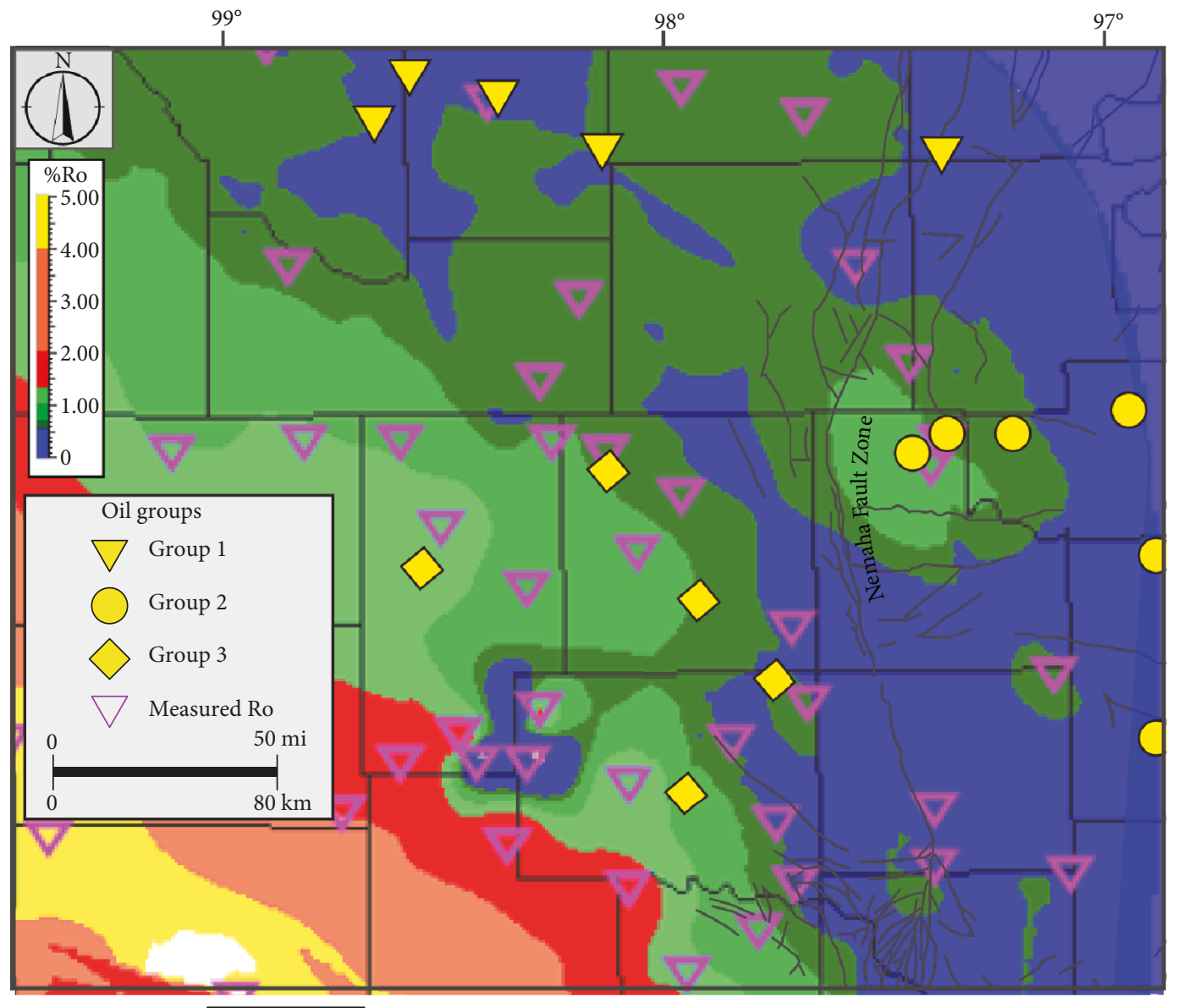

(b)

FIgURE 4: (a) Cross-plot of heptane versus isoheptane ratios to assess crude oil maturity from Mississippian and Woodford of the three oils groups defined in Table 1. Heptane ratio: $100^{*} n$-heptane/cyclohexane +2 -methylhexane +1 ,1-dimethylcyclopentane (DMCP) + 3-methylhexane + 1-cis-3-DMCP + 1-trans-3DMCP + 1-trans-2-DMCP + n-heptane + methylcyclohexane; isoheptane ratio: 2-methylhexane +3-methylhexane/1-cis-3-DMCP + 1-trans-3DMCP + 1-trans-2-DMCP. (b) Regional maturity of the Woodford Shale created using correlation gridding based on vitrinite reflectance measurements available from literature $[2,26,27]$. 
TABLE 3: Key biomarker and diamondoid ratios sensitive to organic matter type and source rock lithology.

\begin{tabular}{|c|c|c|c|c|c|c|c|c|}
\hline Sample ID & $\operatorname{RegC}_{27} / \operatorname{RegC}_{29}$ & $\mathrm{DiaC}_{29} / \operatorname{RegC}_{29}$ & Hop/RegC 29 & ETT/HH & C23TT/Hop & 4,8-DMD & 3,4-DMD & 4,9-DMD \\
\hline \multicolumn{9}{|l|}{ Group 1} \\
\hline Alf-1 & 0.38 & 0.64 & 0.41 & 0.03 & 0.12 & 36.5 & 41.9 & 21.6 \\
\hline Alf-2 & 0.42 & 0.58 & 0.57 & 0.12 & 0.02 & 33.8 & 44.4 & 21.9 \\
\hline Woo-1 & 0.31 & 0.61 & 0.35 & 0.01 & 0.05 & 32.7 & 42.9 & 24.4 \\
\hline Woo-2- & 033 & 0.57 & 0.41 & 0.14 & 0.17 & 30.4 & 47.3 & 22.3 \\
\hline Kay-1 & 0.45 & 0.70 & 0.40 & 0.12 & 0.10 & 28.1 & 46.6 & 25.3 \\
\hline \multicolumn{9}{|l|}{ Group 2} \\
\hline Lin-1 & 0.68 & 0.81 & 0.78 & 0.82 & 0.74 & 43.1 & 40.0 & 16.9 \\
\hline Lin-2 & 0.77 & 0.74 & 0.71 & 0.78 & 0.70 & 41.8 & 38.9 & 19.3 \\
\hline Log-1 & 0.74 & 0.70 & 0.66 & 0.69 & 0.65 & 41.5 & 34.6 & 23.8 \\
\hline $\log -2$ & 0.65 & 0.62 & 0.58 & 0.85 & 0.58 & 44.0 & 33.2 & 22.8 \\
\hline Pay-1 & 0.87 & 0.34 & 0.87 & 0.61 & 0.77 & 46.0 & 34.7 & 19.3 \\
\hline Pay-2 & 0.90 & 0.85 & 0.73 & 0.57 & 0.81 & 47.1 & 28.2 & 24.7 \\
\hline \multicolumn{9}{|l|}{ Group 3} \\
\hline Can-1 & 0.59 & 0.77 & 0.68 & 0.31 & 0.75 & 43.2 & 41.4 & 15.3 \\
\hline Can-2 & 0.66 & 0.54 & 0.41 & 0.41 & 0.65 & 39.4 & 42.4 & 18.3 \\
\hline Kin-1 & 0.45 & 0.58 & 0.70 & 0.78 & 0.87 & 38.3 & 40.4 & 21.3 \\
\hline Kin-2 & 0.66 & 0.41 & 0.51 & 0.18 & 0.25 & 40.1 & 37.6 & 22.4 \\
\hline Bla-1 & 0.87 & 0.79 & 0.55 & 0.74 & 0.45 & 38.8 & 37.0 & 24.2 \\
\hline
\end{tabular}

$\mathrm{RegC}_{29} / \mathrm{RegC}_{27}: \alpha \alpha \mathrm{RC}_{27}$ sterane $/ \alpha \alpha \mathrm{R} \mathrm{C}_{29}$ sterane; $\mathrm{DiaC}_{29} / \mathrm{RegC}_{29}: \mathrm{C}_{29} 13 \beta 17 \alpha 20 \mathrm{R}$ diasterane $/ \mathrm{C}_{29} 13 \beta 17 \alpha$ dia $20 \mathrm{R}+\alpha \alpha \mathrm{R} \mathrm{C}_{29}$ steranes; Hop/RegC ${ }_{29}: \mathrm{C}_{29} 17 \alpha$ hopane/ $\mathrm{C}_{29} 17 \alpha$ hopane $+\mathrm{C}_{29} \alpha \alpha 20 \mathrm{R}$ stigmastane; ETT/HH: sum of extended tricyclic terpanes $\mathrm{C}_{30}$ to $\mathrm{C}_{39} /$ sum of extended tricyclic and $\mathrm{C}_{30} 17 \alpha$ hopane; C23TT/Hop : $\mathrm{C}_{23}$ tricyclic terpane/ $\mathrm{C}_{23}$ tricyclic terpane $+\mathrm{C}_{30} 17 \alpha$ hopane; 4,9-DMD: 4,9-dimethyldiamantane/(sum of 4,8-+4,9-+3,4dimethyldiamantanes); 4,8-DMD: 4,8-dimethyldiamantane/(sum of 4,8-+4,9-+3,4-dimethyldiamantanes); 3,4-DMD: 3,4-dimethyldiamantane/(sum of 4,8-+4,9-+3,4-dimethyldiamantanes).

can be explained based on the trend of thermal maturity across the Anadarko Basin. Particularly, group 3 oils are located at the eastern edge of the Anadarko Basin, where the Woodford Shale has been reported with late oil thermal maturity stage $[26,27]$. Oils located within the Anadarko Shelf showed the highest heptane ratios; however, they are located at a shallower depth where thermal maturity is not sufficient for oil generation (lower than $0.6 \mathrm{VRo} \%$ ), hence these fluids must have resulted from long-distance migration from the Anadarko depocenter where source rocks are buried at higher maturity levels [5]. One exception within group 1 oils is sample Kay-1, which exhibits a mature fluid from its bulk characteristics while plotting within normal oils in Figure 4(a). This in part could be due to evaporative fractionation effect caused by light hydrocarbons partitioning from initially normal oil as a function of migration distance and associated rock-fluid interactions within the carrier beds $[28,29]$. Low heptane ratios of group 2 oils can be classified as normal paraffinic oil, which coincide with the overall maturity of the Woodford Shale and Mississippian mudrocks (0.7 to $0.8 \mathrm{VRo} \%)$ in areas east of the Nemaha Uplift. Figure 4(b) shows a maturity based on measured vitrinite reflectance from the Woodford Shale $[2,26,27]$. The overall maturity trend coincides with group oil maturity stage; however, group 1 exhibits a higher maturity signature than the rocks' maturity where they are produced. This is due to the hydrocarbon charge history which is discussed in the following section.
4.3. Biomarker and Diamondoids. Biomarker and diamondoid distributions in crude oils were investigated to support gasoline-ranged hydrocarbons presented earlier. Listed in Table 3 are selected biomarker and diamondoid ratios. Both sterane and terpane compounds were used in the biomarker ratios with oils showing a wide variation in both biomarkers. For example, group 1 oils are enriched in $\mathrm{C}_{29}$ regular sterane relative to $\mathrm{C}_{27}$, whereas group 2 oils are enriched in $\mathrm{C}_{27}$ regular sterane relative to $\mathrm{C}_{29}$, with a $\operatorname{RegC}_{27} / \mathrm{C}_{29}$ ratio ranging from 0.31 to 0.45 in group 1 , whereas group 2 oils range from 0.65 to 0.90 . Another example from terpane biomarker data is the ratio of $\mathrm{C}_{23}$ tricyclic terpane to hopane $\left(\mathrm{C}_{23} \mathrm{TT} / \mathrm{Hop}\right)$. In this ratio, group 2 oils are enriched in $\mathrm{C}_{23}$ tricyclic terpane relative to hopane, averaging at 0.74 , whereas group 1 oils average at 0.09 , with an intermediate value in group 2 oils (Table 3). Most notably, the extended tricyclic terpanes relative to the hopane (ETT/Hop) ratio exhibit the highest variance among the biomarker ratios. The ETT/Hop ratio ranges from 0.01 to 0.14 in group 1 oils and from 0.57 to 0.85 in group 2 oils. For diamondoid, the relative abundance of selected alkyl diamantane isomers is listed in Table 3. Group 1 oils showed a higher relative abundance of 3,4dimethyl-diamantane, and group 2 oils are slightly higher in 8,4-dimethyldiamantane, whereas group 3 oils exhibit similar abundance between these two isomers (Figure 5(a)).

Biomarker ratio differences are controlled by the source rock composition; for example, enrichment in $\mathrm{C}_{29}$ sterane of group 1 oils has been observed in Woodford-sourced 


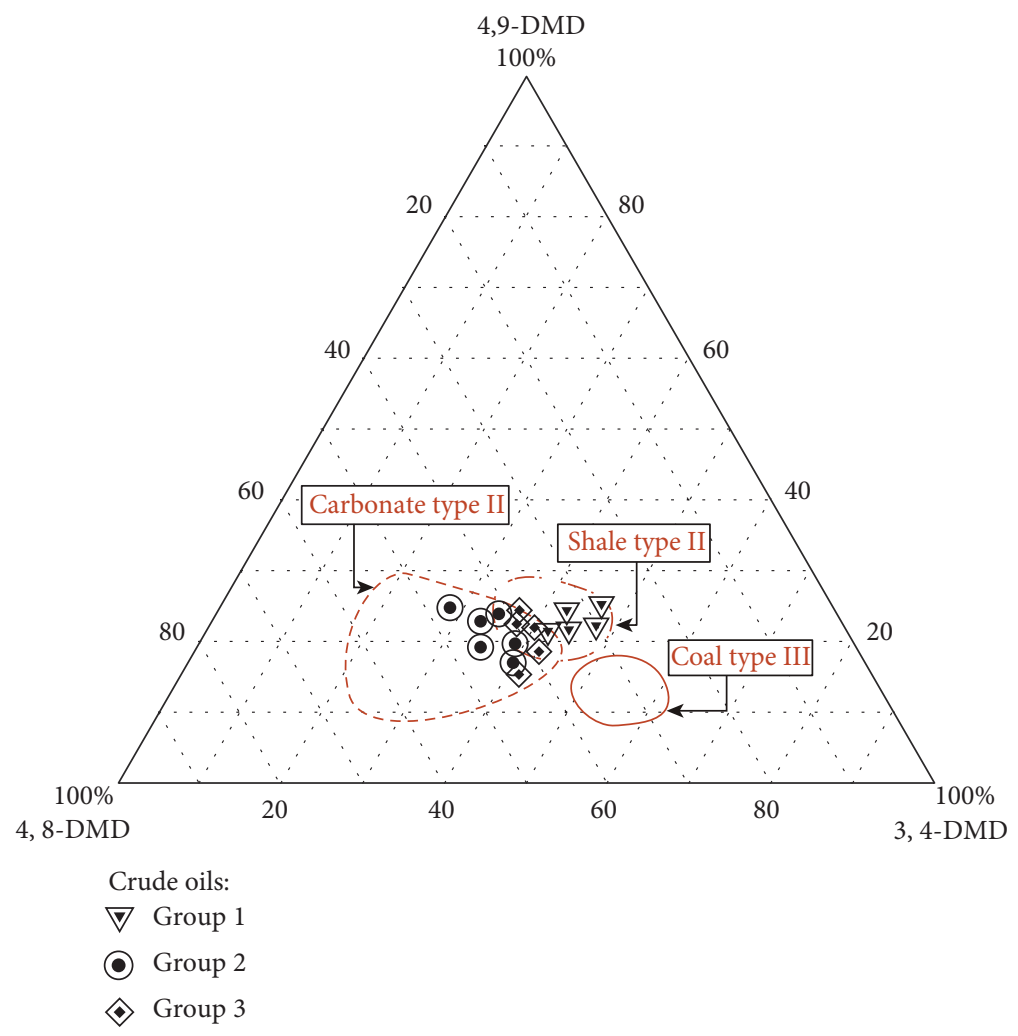

(a)

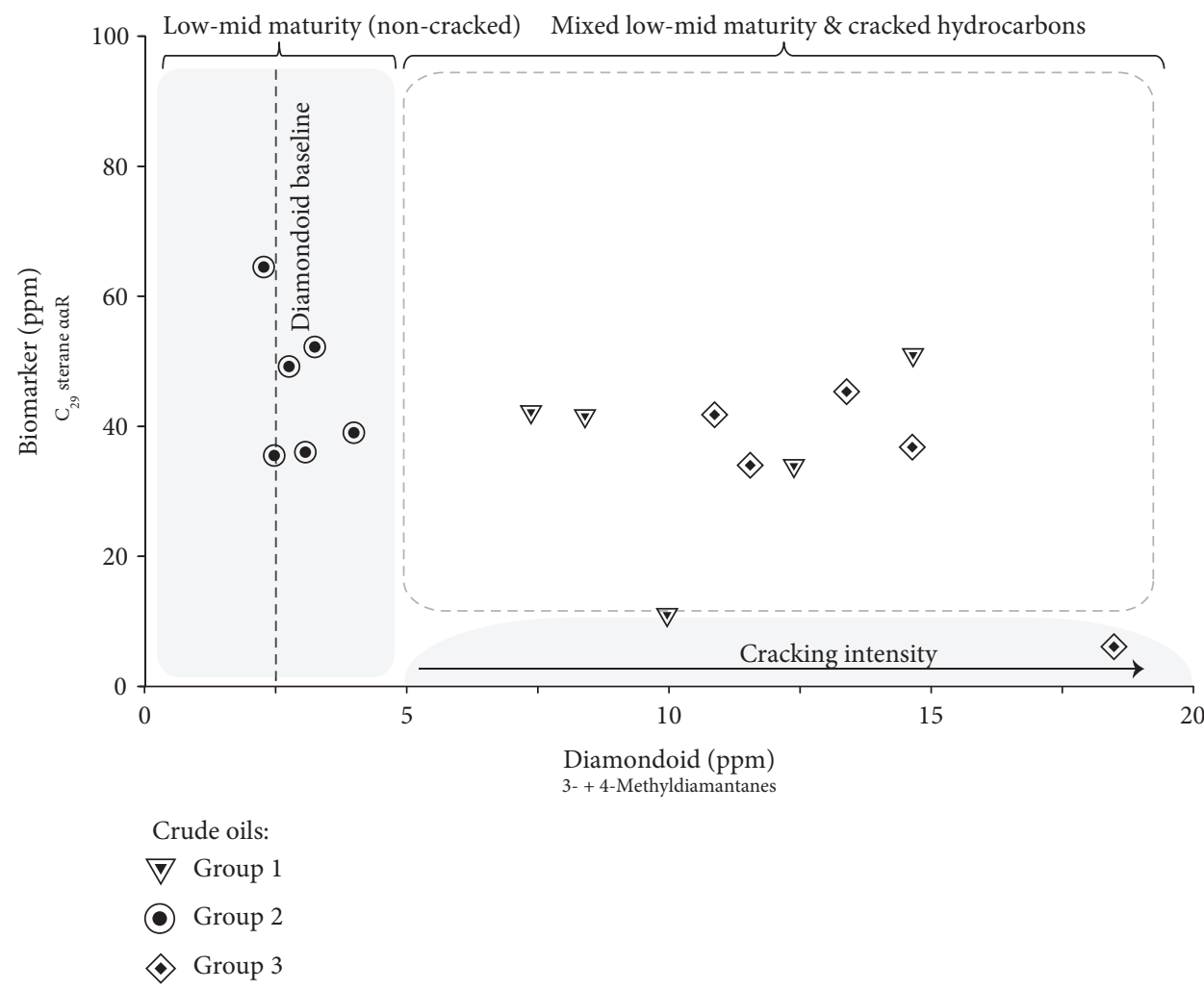

(b)

FIgURE 5: (a) Ternary diagram comparing the relative abundance of three different isomers of dimethyldiamantane, including 4,9-dimethyldiamantane, 4,8-dimethyldiamantane, and 3,4-dimethyldiamantane. Dimethyldiamantanes are measured from $\mathrm{m} / z 201$ mass-fragmentogram. Polygons of different source rock facies is from Schulz et al. [37], (b) Cross-plot for evaluating extent of cracking and oil mixing, comparing 3- + 4-methyldiamantanes versus regular stigmastane biomarker, after [35]. 
crude oil and rock extracts [5, 30]. Despite $\mathrm{C}_{29}$ sterane enrichment in terrigenously derived oils, Palaeozoic marine shales are reported to have a similar fingerprint [31]. $\mathrm{C}_{29}$ sterane is a biomarker that is believed to originate from diagenetic alteration from the parent compound stigmasterol which is typically biosynthesized by eukaryotic organisms [32]. Group 1 oils show enrichment in hopane with a clear homohopane mass-chromatogram trace (Figure 6). Hopane biomarkers are related to bacteriohopanetetrolcompounds found in the bacterial cell membrane (prokaryotic) [33]. Pentacyclic triterpenoids were observed in diverse taxonomic groups of prokaryotic organisms, such as cyanobacteria, purple non-sulfur bacteria, and chemoheterotrophs [34]. Such an abundance of hopanes is consistent with previous studies, in which the abundance of hopanes is evidenced in Woodford Shale extracts. From the oil correlation star diagram in Figure 3, group 1 oils reflect hydrocarbons originating from the Woodford Shale. Additionally, the most notable biomarker characteristic of group 2 is the abundance of extended tricyclic terpanes up to $\mathrm{C}_{42}$ (Figure 6). This is accompanied by depletion of hopane and homohopane relative to tricyclic terpanes, together with higher input of $\mathrm{C}_{27}$ regular sterane relative to the $\mathrm{C}_{29}$ counterpart (Table 3 ). These biomarkerssignature are typical of a Mississippian-sourced oil and a Mississippian-extracted bitumen. [5]. Group 2 oils originate from Mississippian-sourced rocks, evidenced in the narrow star diagram fingerprint in Figure 3. Within group 2 samples, two oils are recovered from wells landed in the Woodford Formation including Lin-1 and Pay-2 (Table 1). However, since these oils show a strong Mississippian biomarker composition and a Mississippian OCSD imprint, it is likely that the stimulated rock volume has exceeded the Woodford into the Mississippian formation resulting in a higher contribution from the Mississippian as opposed to the Woodford, whereas group 3 oils showed a variable signature suggesting a mixing fluid with relatively comparable contributions from the Mississippian and Woodford sources.

Diamondoids are caged hydrocarbons that are usually used to assess oil to gas cracking and thermal maturity due to their thermal ultrastability [35]. Since diamondoids do not possess a clear biological precursor, it is thought that they are formed as a result of the interaction between kerogen and clay minerals within the rock matrix [36]. Hence, the isomeric distribution of certain diamondoids could be sensitive to the source rock lithology. In particular, the alkylated diamantane infers source rock facies by comparing the relative abundance of three isomers of dimethyldiamantanes to distinguish different kerogen contributions (e.g., II-carbonate, type II marl, and type III) [37]. According to ternary plots developed for identifying source rock facies, most of the oils in group 1 plot within marine shale polygon, while group 2 oils are dominantly carbonate-sourced, and group 3 plotted in between group 1 and group 2 (Figure 5(a)). Such observations support biomarker and $\mathrm{C}_{7}$ star diagrams, with group 1 likely sourced from marine shale of the Woodford Shale Formation, group 2 sourced from marine carbonates of the Mississippian Formation, and group 3 likely a mixture of the two end members.
Hydrocarbon mixing and extent of cracking are usually evaluated by comparing methyldiamnatane versus stigmastane biomarker [35]. Figure 5(b) shows the different oil groups and their content of methyldiamondoid versus stigmastane. Both groups 1 and 3 are clearly enriched in both stigmastane and diamondoids, whereas group 2 oils are only enriched in stigmastane and depleted in diamondoids. Moreover, group 2 oils plot at the diamondoid baseline, which has been defined from immature rock extracts [5]. This suggests that group 1 and group 3 are a mixture of hydrocarbonbearing high- and low-maturity signatures, whereas group 2 oils are unmixed oil with early to peak-oil maturity level. However, the condensate sample Bla-1 is the only exception which shows a trace amount of stigmastane, suggesting that this condensate is a highly cracked fluid which is unmixed with black oil. From a petroleum systems perspective, such hydrocarbon charge trend coincides with previous studies that postulated that oils within the Anadarko Shelf are a result of an episodic hydrocarbon charge from the depocenter of the Anadarko Basin, whereas oils east of the Nemaha Uplift are a result of localized hydrocarbon charge with no contribution from deep Anadarko [5]. Moreover, this explains the inconsistent signature between the isoheptane ratio and buck crude oil parameters of group 1 and group 3 oils, whereas the former suggests highly mature fluids, whereas the latter indicates black oils.

4.4. Phenols. Results of phenol concentrations in crude oils are shown in Figure 7, which compares the concentration of phenols to the sum of cresols. The phenol concentration is higher than $1 \mathrm{ppm}$ in all samples from group 3, whereas group 1 and group 2 oils exhibit lower phenol concentrations (lower than $0.5 \mathrm{ppm}$ ) (Figure 7). A similar trend is also observed in the concentration of cresols, including all three cresol isomers (i.e., ortho-cresol, meta-cresol, and paracresol), with group 3 higher than $1 \mathrm{ppm}$ in cresols while groups 1 and 2 are low in cresols.

Phenols are a broad class of aromatic hydrocarbons containing a hydroxyl group, with phenol as the simplest compound in this class consisting of a benzene ring bound to a hydroxyl group. The alkylated counterparts are naturally occurring in petroleum and also found in sedimentary organic matter. Of particular interest to this study are cresols (also known as hydroxytoluene) which exhibit a similar structure to phenol with an additional methyl group. Cresols are found in three main isomers; they are o-cresol, m-cresol, and p-cresol. Phenolic compounds are water-soluble polar compounds, and they can be used to assess crude oil secondary alteration such as water-washing [38]. Based on a series of core-flooding experiments with hydrocarbons aimed at stimulating petroleum migration in the subsurface, phenols dramatically change in abundance between initial oil and migrated oil [39]. Sorption effects on hydrophilic compounds such as phenols are significant and ultimately result in phenol depletion as a function of crude oil interaction with water [38]. Crude oil and water interaction can result from oil migration through carrier bed or water-washing in the reservoir, with the latter being the dominant factor influencing phenol distribution [40]. 


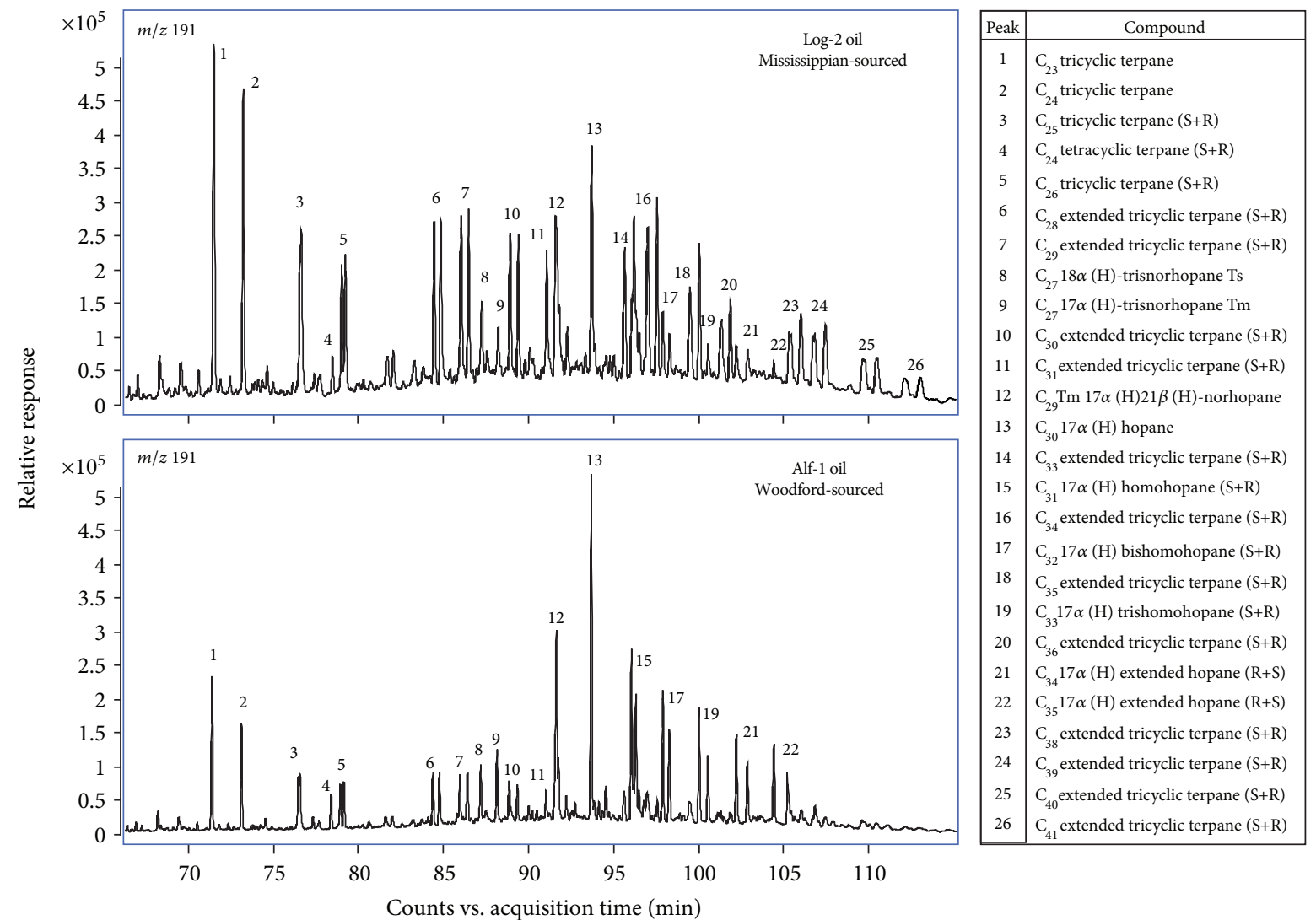

FIGURE 6: Mass chromatogram $(\mathrm{m} / z$ 191) showing terpane biomarker distribution in the saturate hydrocarbons comparing two end members of Mississippian sourced (Log-2) and Woodford sourced (Alf-1) crude oils. Note the enrichment of extended tricyclic terpanes up to $\mathrm{C}_{41}$ in Mississippian-sourced oil and is depleted in Woodford-sourced oil.

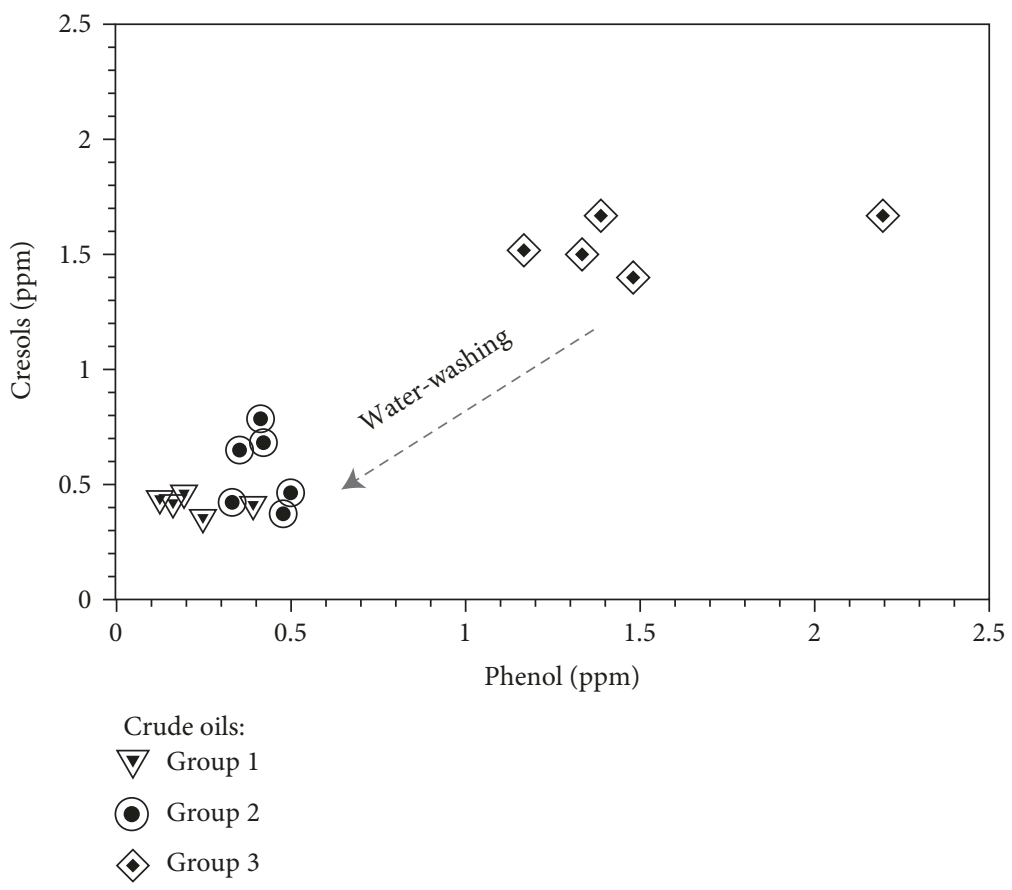

FIGURE 7: Cross-plot of crude oil samples comparing concentration of phenol in the $x$-axis against the sum of cresols which includes ortho-cresol, meta-cresol, and para-cresol. 
The overall phenol depletion of the examined crude oils is likely related to water-washing. This is also corroborated by evidence observed from an oil alteration star diagram discussed earlier (Figure 3). Particularly, oil samples from group 1 and group 2 exhibit a trace amount of phenols and lack toluene (Figures 3 and 7). Both of these oils are located within the Mississippian Limestone Play (Figure 1). The Mississippian Limestone Play is well-known for fractured highly permeable shallow reservoirs that are economically attractive to drill; however, significant volumes of associated saltwater production influence the economic success in such a play $[41,42]$. The inherent high permeability and associated water in Mississippian reservoir suggest a fluid dynamic system in which hydrocarbons are consistently interacting with water resulting in preferential depletion of hydrophilic compounds from crude oil, as observed in group 1 and group 2 oils. In contrast, group 3 oils are relatively higher in phenols, as well as toluene, indicating a lower water-washing effect (Figures 3 and 7). Group 3 oils are produced from tight mudrocks within the STACK Play, which requires hydraulic stimulation to produce hydrocarbons (Figure 1) [42]. In such reservoir settings with ultralow permeability where oils have limited interaction with formation water, intact phenols and toluene compounds are present in crude oil. It is important to note that group 3 is still low in hydrophilic compounds when compared to other crude oils from different basins; however, those compounds are still intact, whereas group 1 and group 2 are nearly absent. Group 3 oils could have had initially a higher phenol content within the reservoir, and a partial loss of phenols occurred as a result of water injection during hydraulic stimulation.

\section{Conclusions}

Light hydrocarbon geochemistry provides an effective tool to elucidate hydrocarbon source, maturity, and secondary alterations across Mississippian reservoirs within the Anadarko Basin of Oklahoma by the following:

(i) Two distinct petroleum fingerprints for Mississippian mudrocks and Woodford Shale petroleum source rocks using light hydrocarbons have been identified and further supported by biomarker and diamondoid evidence

(ii) Oils produced from the Mississippian limestone play within the Anadarko Shelf (group 1) exhibit a distinct fingerprint and sourced from the Woodford Shale

(iii) Mississippian oils in central Oklahoma (group 2) exhibit a distinct fingerprint and sourced from Mississippian mudrocks

(iv) Oils within STACK play (group 3) are mixtures of these two different sources

(v) Thermal maturity based on light hydrocarbon parameters indicates that oils from the Anadarko Shelf (group 1) are of the highest maturity, followed by STACK play oils (group 3) and central Oklahoma oils (group 2). Both group 1 and 3 oils are a result of episodic hydrocarbon charge of early maturity mixed with highly mature hydrocarbons

(vi) Water-washing is a major secondary alteration affecting hydrocarbon produced from the Mississippian Limestone play within the Anadarko Shelf and (group-1) and central Oklahoma (group 2), whereas STACK play oils are largely unaltered

\section{Data Availability}

The data used to support the findings of this study are available from the corresponding author upon request.

\section{Disclosure}

Part of this manuscript has been presented at the AAPG Annual Convention and Exhibition 2016 in Calgary, Canada.

\section{Conflicts of Interest}

The authors declare that there is no conflict of interest regarding the publication of this paper.

\section{Acknowledgments}

Especial thanks are due to Chevron Basin Modeling Centre, Berg-Hughes Centre, Geochemical and Environmental Research Group, and Saudi Aramco for technical and financial support.

\section{References}

[1] K. A. Franks, The Oklahoma Petroleum Industry, University of Oklahoma Press, Norman, OK, USA, 1980.

[2] B. J. Cardott, "Oklahoma shale resource plays: Oklahoma geological survey," Oklahoma Geology Notes, vol. 76, pp. 21-30, 2017.

[3] D. Brown, "Oklahoma plays offer untapped potential," $A A P G$ Explorer, vol. 35, pp. 8-10, 2014.

[4] I. Al Atwah, J. Puckette, and T. Quan, "Petroleum geochemistry of the Mississippian limestone play, Northern Oklahoma, USA: evidence of two different charging mechanisms east and west of the Nemaha Uplift," 2015, December 2018, Article \#10773: AAPG Search and Discovery, http://www. searchanddiscovery.com/pdfz/documents/2015/ 10773alatwah/ndx_alatwah.pdf.html.

[5] I. Al Atwah, J. Puckette, J. Pantano, K. Arouri, and J. M. Moldowan, "Chapter 13: organic geochemistry and crude oil source rock correlation of Devonian-Mississippian petroleum systems in Northern Oklahoma," in Mississippian Reservoirs of the Midcontinent, J. M. G. G. M. Grammer, J. O. Puckette, P. Jaiswal, S. J. Mazzullo, M. J. Pranter, and R. H. Goldstein, Eds., AAPG Memoir 122, 2019.

[6] D. W. Wang and R. P. Philp, "Geochemical study of potential source rocks and crude oils in the Anadarko Basin, Oklahoma," AAPG Bulletin, vol. 81, pp. 249-275, 1997. 
[7] K. S. Johnson, "Geologic evolution of the Anadarko Basin," in Anadarko Basin Symposium, K. S. Johnson, Ed., vol. 90, pp. 3-12, Oklahoma Geological Survey, Norman, Oklahoma, 1989.

[8] S. Feinstein, "Subsidence and thermal history of southern Oklahoma aulacogen: implications for petroleum exploration," American Association of Petroleum Geologists Bulletin, vol. 65, no. 12, pp. 2521-2533, 1981.

[9] W. E. Ham, R. E. Denison, and C. A. Merritt, "Basement rocks and structural evolution of southern Oklahoma," American Association of Petroleum Geologists Bulletin, vol. 48, p. 529, 1964.

[10] K. S. Johnson, T. W. Amsden, R. E. Denison et al., "Southern Midcontinent Region," in Sedimentary Cover, North American Craton: U.S., L. L. Sloss, Ed., vol. 2, pp. 307-360, The Geological Society of America, Evanston, IL, USA, 1988.

[11] L. Jordan and T. L. Rowland, "Mississippian rocks in northern Oklahoma," Tulsa Geological Society Digest, vol. 27, pp. 124136, 1959.

[12] E. N. Wilson, W. L. Watney, and G. M. Grammer, "An overview of the giant heterogeneous Mississippian carbonate system of the midcontinent: ancient structure, complex stratigraphy, conventional traps and unconventional technology in a high fluid volume world," in Mississippian Reservoirs of the Midcontinent, J. M. G. G. M. Grammer, J. O. Puckette, P. Jaiswal, S. J. Mazzullo, M. J. Pranter, and R. H. Goldstein, Eds., AAPG Memoir 116, 2017.

[13] M. C. Gilbert, "Speculations on the origin of the Anadarko basin," in Basement Tectonics 7, R. Mason, Ed., vol. 1, pp. 195-208, Springer, 1992.

[14] W. J. Perry, "Tectonic evolution of the Anadarko Basin Region, Oklahoma," Bulletin, vol. 1866-A, pp. A1-A15, 1989.

[15] C. Kluth, "Plate tectonics of the ancestral rocky mountains: part III. Middle rocky mountains," in Paleotectonics and Sedimentation in the Rocky Mountain Region, United States, J. E. Peterson, Ed., pp. 353-369, American Association of Petroleum Geologists, Memoir 41, 1986.

[16] C. A. Ross, "Late Paleozoic collision of North and South America," Geology, vol. 7, no. 1, pp. 41-44, 1979.

[17] D. L. Garner and D. L. Turcotte, "The thermal and mechanical evolution of the Anadarko basin," Tectonophysics, vol. 107, no. 1-2, pp. 1-24, 1984.

[18] M. D. Lewan, M. J. Kotarba, J. B. Curtis, D. Więcław, and P. Kosakowski, "Oil-generation kinetics for organic facies with type-II and -IIS kerogen in the menilite shales of the Polish Carpathians," Geochimica et Cosmochimica Acta, vol. 70, no. 13, pp. 3351-3368, 2006.

[19] H. I. Halpern, "Development and applications of lighthydrocarbon-based star diagrams," AAPG Bulletin, vol. 79, pp. 801-815, 1995.

[20] F. D. Mango, "An invariance in the isoheptanes of petroleum," Science, vol. 237, no. 4814, pp. 514-517, 1987.

[21] S. E. Palmer, "Effect of water washing on $\mathrm{C}_{15+}$ hydrocarbon fraction of crude oils from Northwest Palawan, Philippines," AAPG Bulletin, vol. 68, pp. 137-149, 1984.

[22] R. C. Burruss and J. R. Hatch, "The geochemistry of oils and hydrocarbon source rocks, Greater Anadarko basin: evidence for multiple sources of oils and long distance oil migration," in Anadarko Basin Symposium, Circular 90, K. S. Johnson, Ed., pp. 53-64, Oklahoma Geological Survey, Norman, Oklahoma, 1989.
[23] K. F. M. Thompson, "Gas-condensate migration and oil fractionation in deltaic systems," Marine and Petroleum Geology, vol. 5, no. 3, pp. 237-246, 1988.

[24] K. F. M. Thompson, "Classification and thermal history of petroleum based on light hydrocarbons," Geochimica et Cosmochimica Acta, vol. 47, no. 2, pp. 303-316, 1983.

[25] J. M. Hunt, J. K. Whelan, and A. Y. Huc, "Genesis of petroleum hydrocarbons in marine sediments," Science, vol. 209, no. 4454, pp. 403-404, 1980.

[26] B. J. Cardott, "Thermal maturation of the Woodford Shale in the Anadarko Basin," in Anadarko Basin Symposium, Circular 90, K. S. Johnson, Ed., pp. 32-46, Oklahoma Geological Survey, Norman, Oklahoma, 1989.

[27] B. J. Cardott, "Thermal maturity of Woodford Shale gas and oil plays, Oklahoma, USA," International Journal of Coal Geology, vol. 103, pp. 109-119, 2012.

[28] L. I. P. Dzou and W. B. Hughes, "Geochemistry of oils and condensates, K Field, offshore Taiwan: a case study in migration fractionation," Organic Geochemistry, vol. 20, no. 4, pp. 437-462, 1993.

[29] K. F. M. Thompson, "Fractionated aromatic petroleums and the generation of gas-condensates," Organic Geochemistry, vol. 11, no. 6, pp. 573-590, 1987.

[30] A. M. Romero and R. P. Philp, "Organic geochemistry of the Woodford shale, southeastern Oklahoma: how variable can shales be?," AAPG Bulletin, vol. 96, no. 3, pp. 493-517, 2012.

[31] J. M. Moldowan, W. K. Seifert, and E. J. Gallegos, "Relationship between petroleum composition and depositional environment of petroleum source rocks," AAPG Bulletin, vol. 69, pp. 1255-1268, 1985.

[32] K. Peters, C. C. Walters, and J. M. Moldowan, The Biomarker Guide: Biomarkers and Isotopes in the Environment and Human History, vol. 2, Cambridge University Press, 2005.

[33] G. Ourisson, P. Albrecht, and M. Rohmer, "The microbial origin of fossil fuels," Scientific American, vol. 251, no. 2, pp. 44-51, 1984.

[34] M. Rohmer, P. Bouvier-Nave, and G. Ourisson, "Distribution of Hopanoid triterpenes in prokaryotes," Microbiology, vol. 130, no. 5, pp. 1137-1150, 1984.

[35] J. E. Dahl, J. M. Moldowan, K. E. Peters et al., "Diamondoid hydrocarbons as indicators of natural oil cracking," Nature, vol. 399, no. 6731, pp. 54-57, 1999.

[36] Z. Wei, J. M. Moldowan, and A. Paytan, "Diamondoids and molecular biomarkers generated from modern sediments in the absence and presence of minerals during hydrous pyrolysis," Organic Geochemistry, vol. 37, no. 8, pp. 891-911, 2006.

[37] L. K. Schulz, A. Wilhelms, E. Rein, and A. S. Steen, "Application of diamondoids to distinguish source rock facies," Organic Geochemistry, vol. 32, no. 3, pp. 365-375, 2001.

[38] P. Taylor, S. Larter, M. Jones, J. Dale, and I. Horstad, "The effect of oil-water-rock partitioning on the occurrence of alkylphenols in petroleum systems," Geochimica et Cosmochimica Acta, vol. 61, no. 9, pp. 1899-1910, 1997.

[39] S. Larter, B. Bowler, E. Clarke et al., "An experimental investigation of geochromatography during secondary migration of petroleum performed under subsurface conditions with a real rock," Geochemical Transactions, vol. 1, no. 1, p. 54, 2000.

[40] C. A. Peters, C. Hallmann, and S. C. George, "Phenolic compounds in oil-bearing fluid inclusions: implications for water-washing and oil migration," Organic Geochemistry, vol. 118, pp. 36-46, 2018. 
[41] A. P. Hall, The Kansas Oil and Gas Industry-an Enduring Model of High-Tech Entrepreneurship, The Center for Applied Economics, Technical Report 12-1116, University of Kansas School of Business, 2012.

[42] K. E. Murray, "State-scale perspective on water use and production associated with oil and gas operations, Oklahoma, U.S.," Environmental Science \& Technology, vol. 47, no. 9, pp. 4918-4925, 2013. 

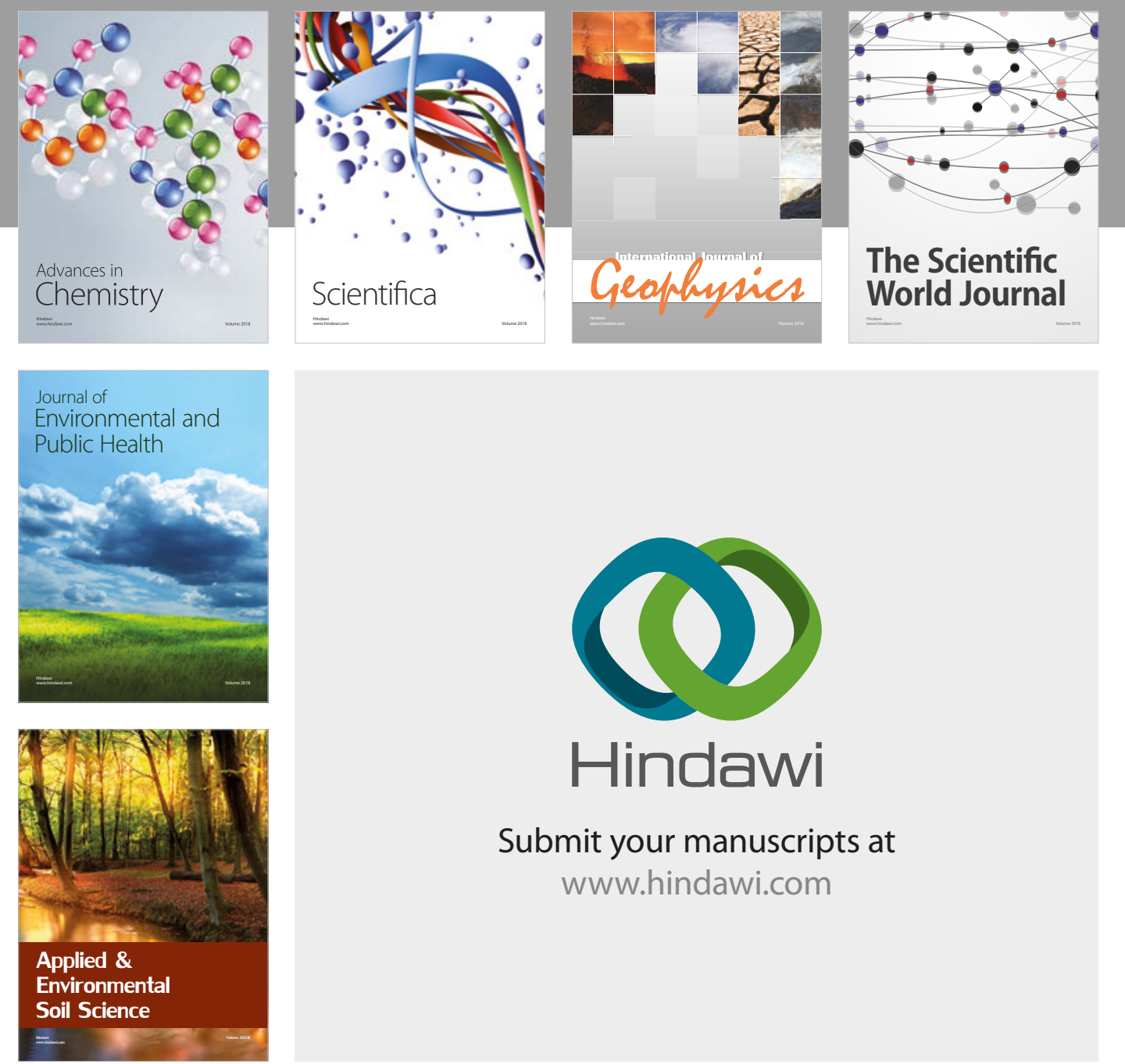

The Scientific

\section{World Journal}
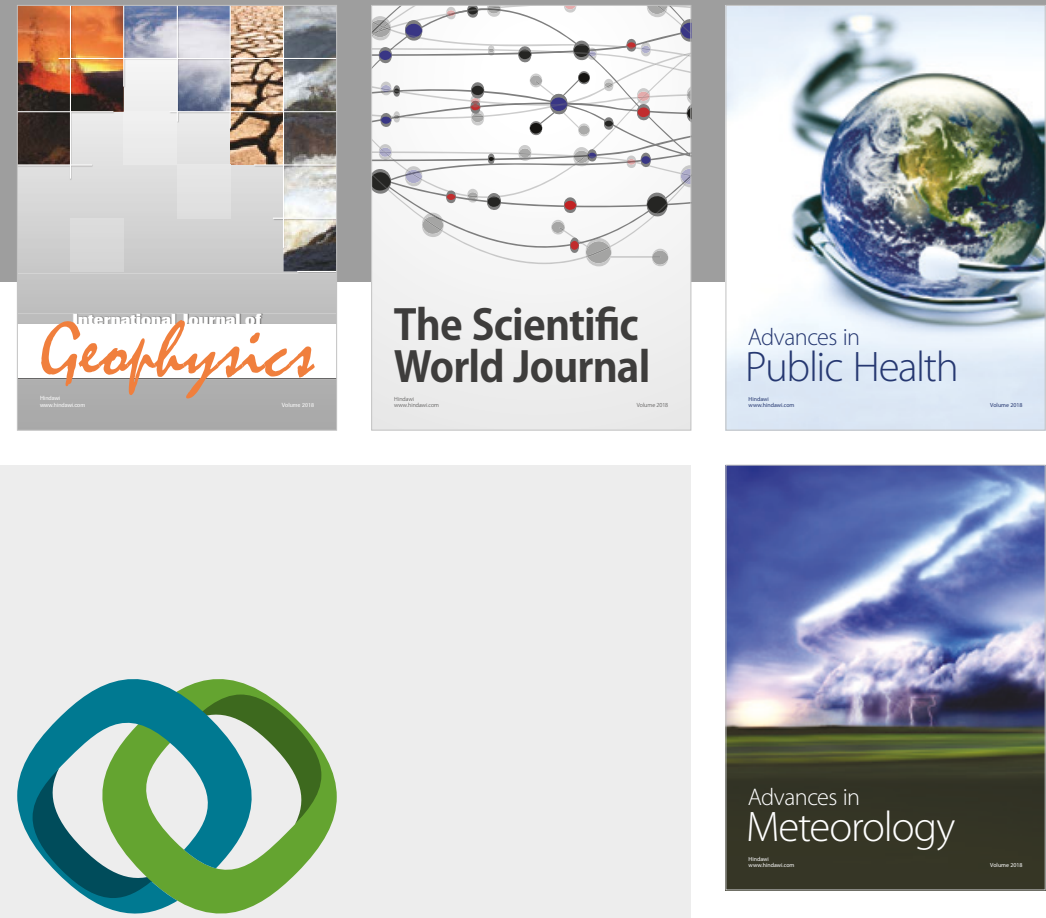

Advan

Public Health

\section{Hindawi}

Submit your manuscripts at

www.hindawi.com
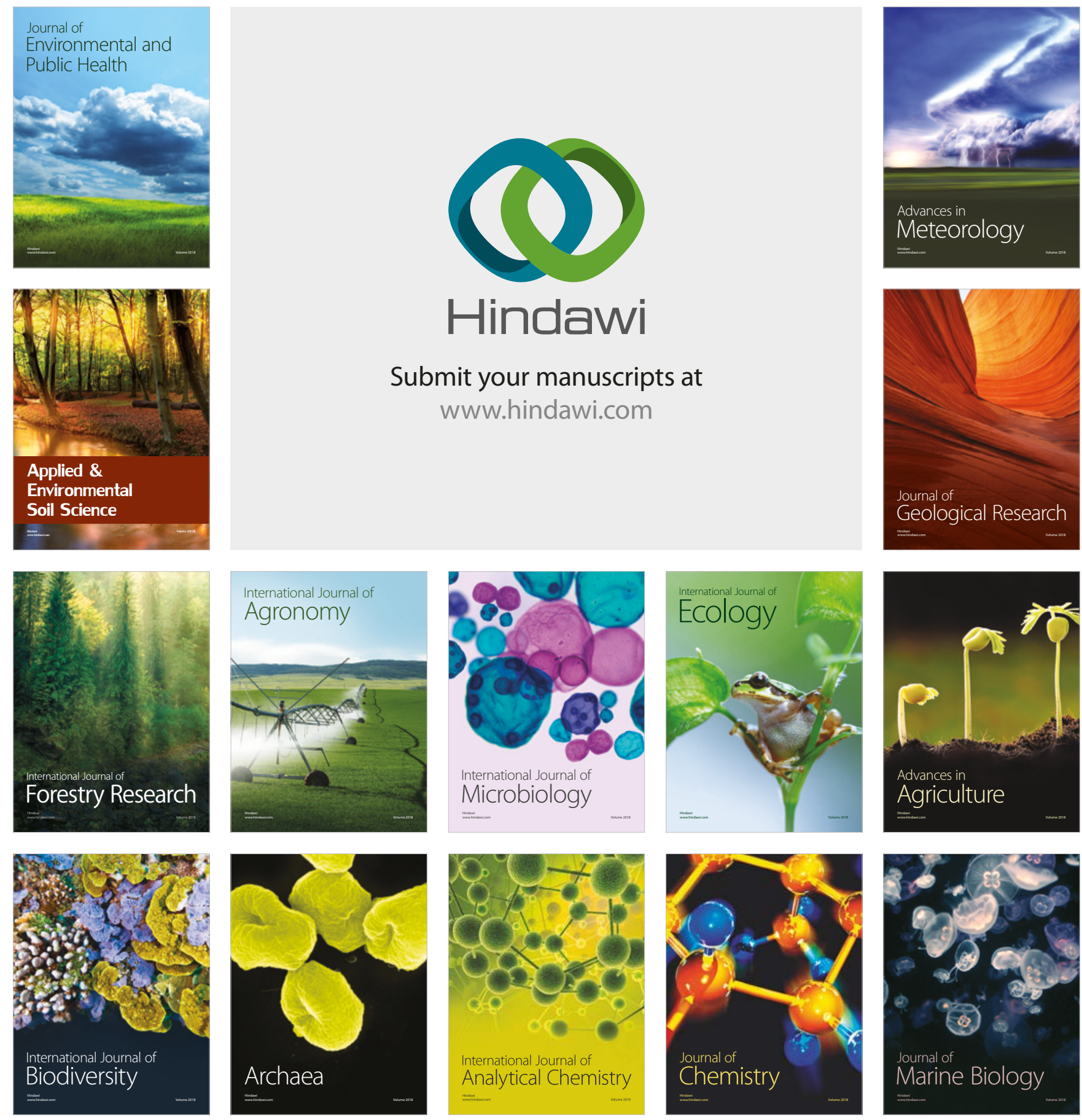